\title{
Assessment of Splanchnic Perfusion with Gastric Tonometry in the Immediate Postoperative Period of Cardiac Surgery in Children
}

\author{
Renato Lopes de Souza, Werther Brunow de Carvalho, Mgud Ange Maluf, Antonio Carlos Canvalho
}

\author{
São Paulo, SP - Brazil
}

\begin{abstract}
Objective - A prospective, nonrandomized clinical study to assess splanchnic perfusion based on intramucosal $\mathrm{pH}$ in the postoperative period of cardiac surgery and to check the evolution of patients during hospitalization.
\end{abstract}

Methods - We studied 10 children, during the immediate postoperative period after elective cardiac surgery. Sequential intramucosal pH measurements were taken, without dobutamine (TO) and with $5 \mathrm{mcg} / \mathrm{kg} / \mathrm{min}$ (T1) and $10(T 2) \mathrm{mcg} / \mathrm{kg} / \mathrm{min}$. In the pediatric intensive care unit, intramucosal pH measurements were made on admission and 4, 8, 12, and 24 hours thereafter.

Results - The patients had an increase in intramucosal $\mathrm{pH}$ values with dobutamine $10 \mathrm{mcg} / \mathrm{kg} / \mathrm{min}[7.19 \pm 0.09$ (T0), 7.16 $\pm 0.13(T 1)$, and 7.32 $\pm 0.16(T 2)],(p=0.103) . D u$ ring the hospitalization period, the intramucosal $\mathrm{pH}$ values were the following: $7.20 \pm 0.13$ (upon admission), $7.27 \pm 0.16$ (after 4 hours), $7.26 \pm 0.07$ (after 8 hours), $7.32 \pm 0.12$ (after 12 hours), and $7.38 \pm 0.08$ (after 24 hours), $(p=0.045)$. No deaths occurred, and none of the patients developed multiple organ and systems dysunction.

Conclusion - An increase in and normalization of intramucosal pH was observed after dobutamine use. Measurement of intramucosal $\mathrm{pH}$ is a type of monitoring that is easy to perform and free of complications in children during the postoperative period of cardiac surgery.

Key words: $\quad$ pH, splanchnic perfusion, dobutamine, gastric tonometry, pediatric cardiac surgery

Universidade Federal de São Paulo - Escola Paulista de Medicina Mailing address: Renato Lopes de Souza - Praça Louveira, 12 - 03080-050 - São Paulo, SP - Brazil - E-mail: acarloscc@ cardiol.br
In critically ill patients, the fundamental and initial organic lesion mechanism is tissue or cellular hypoxia. When a lack of oxygen occurs, the adenosine triphosphate (ATP) hydrolysis rate exceeds the synthesis rate, with a $\mathrm{pH}$ drop as a consequence. The low oxygen supply makes the organism mobilize its anaerobic sources of energy to meet the energy demand of cells and maintain their integrity ${ }^{1}$.Under such circumstances, $\mathrm{CO}_{2}$ production in all tissues is directly related to the $\mathrm{O}_{2}$ consumption rate.

The intracellular $\mathrm{pH}$ fall seems to be crucial for the cell deterioration process, and this information is fundamental for the diagnosis of anaerobiosis onset; it would be interesting to identify which tissues are the first to suffer hypoxia and acidosis and to find feasible ways of determining this acidosis ${ }^{2}$.

The use of regional measures is essential, assuming that these areas might be early markers of systemic hypoperfusion. Other cellular metabolism markers can be used, such as arterial lactate, which is also a systemic measurement, frequently with a late elevation, because the liver has a great lactate oxidation capacity ${ }^{3}$. Global measurements give us little information about oxygen utilization and requirements at the tissue level ${ }^{4}$. Gastric tonometry contrasts with the poor sensitivity of some invasive methods for systemic assessment of oxygenation. Intramucosal $\mathrm{pH}$ measurement has been evaluated as a minimally invasive method capable of providing early information about inadequate tissue oxygenation even in clinically stable patients. However, intramucosal $\mathrm{pH}$ needs further study for the establishment of its critical value, where $\mathrm{O}_{2}$ consumption becomes transport-dependent ${ }^{5}$.

Approximately 50-60\% of patients in the postoperative period of major surgeries and $80 \%$ of patients in intensive care units are believed to be liable to develop transient episodes of dysoxia (imbalance between oxygen supply and consumption), which are not diagnosed because apparently these patients are normal, that is, without detectable hemodynamic changes by the conventional methods, and 
their compensation mechanisms maintain them this way ${ }^{6}$.

Our objective in this study was to identify the intramucosal pH alterations during the patients' evolution in the immediate postoperative period of cardiac surgery in clinically stable children and to find out whether any alteration occurs in gastrointestinal perfusion when increasing doses of dobutamine are administered.

\section{Methods}

The study protocol was approved by the ethics committee of the university, and a written consent was obtained from the parents or responsible persons. The prospective, nonrandomized clinical study was carried out in the pediatric intensive care unit, including only patients who had undergone elective cardiac surgery with extracorporeal circulation, and excluding those who had any kind of contraindication for the passage of a nasogastric lead.

Ten children with a mean age of $41.3 \pm 25.1$ months, a mean weight of $12.12 \pm 2.98 \mathrm{~kg}$, and a mean height of $92.2 \pm$ $13.53 \mathrm{~cm}$ were evaluated. Their congenital cardiopathies and respective surgical corrections are presented in Table I. Patients were not divided into groups of those with cyanogenic or acyanogenic cardiopathies.

The patients received as a preanesthetic medication either midazolam or ketamine. Induction was made with an oxygen mask and isoflurane at a maximum concentration of $1 \%$. Neuromuscular block was performed with pancuronium and anesthesia maintenance with fentanyl. Patients were medicated before surgery and during the postoperative period, with $3 \mathrm{mg} / \mathrm{kg} /$ day intravenous ranitidine every 8 hours ${ }^{7}$. Extracorporeal circulation was carried out by nonpulsatile flow, and slight hypothermia or normothermia was applied.

In the operating room, NGS Catheter Trip tonometry leads were available (gastric tonometer and sump - Tonometrics, Inc., Worcester, MA, USA). After ensuring the localization of the lead in the stomach through auscultation followed by X-rays, $2.5 \mathrm{~mL}$ of $0.9 \%$ saline solution were infused into the tonometer balloon (Fig. 1).

To calculate intramucosal $\mathrm{pH}$, the Radiometer Copenhagen ABL 330 gasometry device was considered the stan-

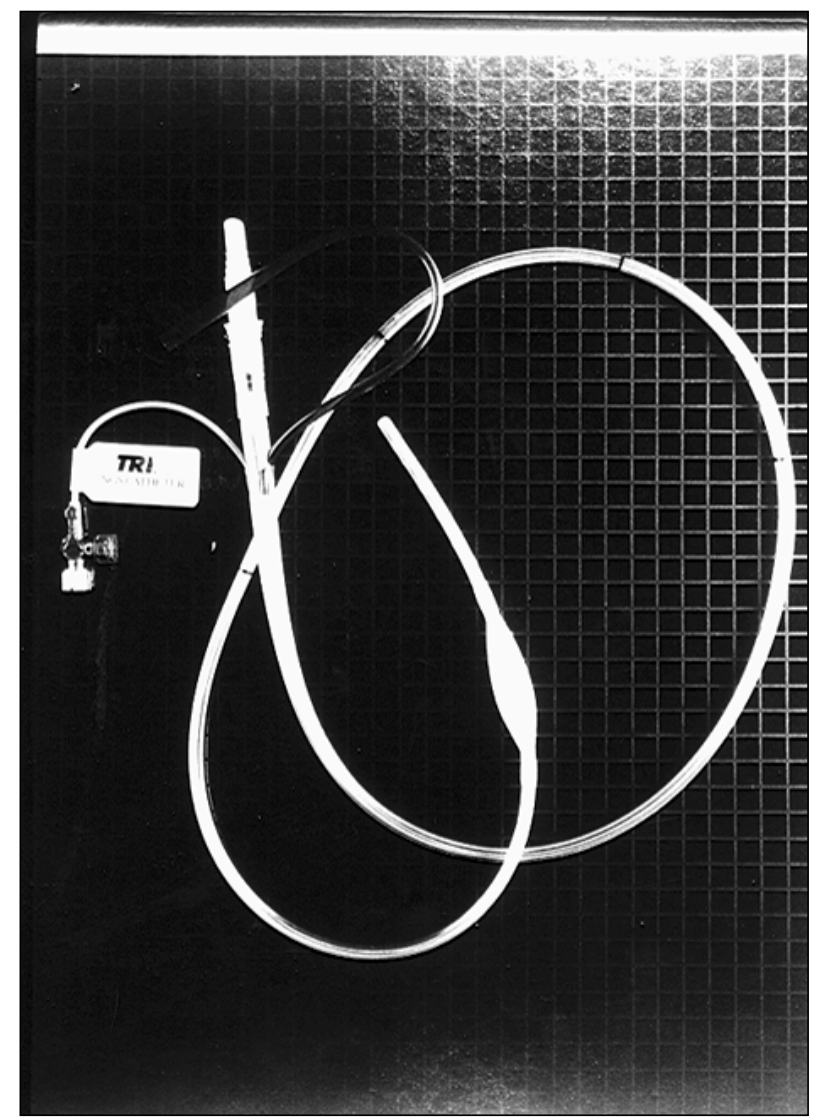

Fig. 1 - Assessment of splanchnic perfusion by using gastric tonometry during the postoperative period of cardiac surgery in children.

dard. The intramucosal $\mathrm{pH}$ was calculated using the saline solution $\mathrm{pCO}_{2}$ measurement $\left(\mathrm{pCO}_{2 \mathrm{ss}}\right)$, corrected by the equilibrium time as recommended by the manufacturer, and arterial bicarbonate $\left(\mathrm{HCO}_{3}\right.$ art. $)$ with the Henderson-Hasselbach equation.

Upon admission to the pediatric intensive care unit, the patients' temperature was normalized, and they were put on intermittent mandatory ventilation. Intramucosal $\mathrm{pH}$ measurements were taken until the lead was removed, which occurred after extubation or when enteral feeding started. None of the patients was extubated or received enteral fee-

\begin{tabular}{|c|c|c|c|c|}
\hline $\begin{array}{l}\text { Age } \\
\text { Months }\end{array}$ & $\begin{array}{c}\text { Weight } \\
\mathrm{kg}\end{array}$ & $\begin{array}{c}\text { Height } \\
\text { am }\end{array}$ & Diagnoses & Surgical Correction \\
\hline 87 & 17.2 & 115 & Mitral failure & Mitral valvoplasty \\
\hline 36 & 12 & 92 & Double entrance of LV and pulmonary artery bandage & Bidirectional cavo-pulmonary shunt \\
\hline 22 & 11.3 & 85 & Abnormal origin of left coronary & Reimplantation of left coronary artery into the aorta \\
\hline 68 & 14.5 & 106 & IVC & Ventriculoseptoplasty \\
\hline 24 & 10.4 & 85 & Ib tricuspid atresia & Enlargement of IAC and bidirectional cavopulmonary \\
\hline 74 & 16.8 & 112 & Double exit of LV + IVC + PS & Total correction with RV- PT tube \\
\hline 26 & 9.8 & 83 & Double exit of RV + PS & Atrioseptectomy and central aorto-pulmonary shunt \\
\hline 27 & 10.1 & 82 & Residual IVC in PO Fallot's Tetralogy & Closure of residual IVC \\
\hline 32 & 10 & 82 & IVC & Ventriculoseptoplasty \\
\hline 17 & 9.1 & 80 & IVC & Ventriculoseptoplasty \\
\hline
\end{tabular}


ding within the first $24 \mathrm{hr}$ of hospitalization. The assisting doctor's conduct was not influenced by the tonometry results, because they were unknown to him. The first measurements were made without any drug being given (immediately after admission), then with $5 \mathrm{mcg} / \mathrm{kg} / \mathrm{min}$ and $10 \mathrm{mcg} /$ $\mathrm{kg} / \mathrm{min}$ of dobutamine, after a 90 -minute waiting period from the change in drug infusion until the measurement was made. After patients were admitted to the pediatric intensive care unit, the measurements were compared, all of them having been made with patients receiving dobutamine (except on admission), at the following times: admission, 4, 8, 12, and $24 \mathrm{hrs}$.

Clinical parameters (diuresis, heart rate, RR, capillary filling, thermal gradient), electrocardiography, mean invasive arterial pressure, central venous pressure, and pulse oxymetry were used to monitor patients.

The effect of giving dobutamine was analyzed by comparing the variables in 3 different situations: without dobutamine, with dobutamine $5 \mathrm{mcg} / \mathrm{kg} / \mathrm{min}$ and $10 \mathrm{mcg} / \mathrm{kg} / \mathrm{min}$. For this analysis, the Friedman assay $\left(\chi_{\mathrm{r}}^{2}\right)$ was used. The significance level adopted was $0.05(\alpha=5 \%)$.

\section{Results}

The intramucosal $\mathrm{pH}$ values and mean in the 3 scenarios (no drug, $5 \mathrm{mcg} / \mathrm{kg} / \mathrm{min}$ dobutamine, and $10 \mathrm{mcg} / \mathrm{kg} / \mathrm{min}$ dobutamine) are shown on Table II. These values did not show any statistically significant difference $(\mathrm{p}=0.103)$, but the patients showed a tendency toward an increase in intramucosal $\mathrm{pH}$.

The mean period of extracorporeal circulation was 62.4 min and of anoxia was $43.5 \mathrm{~min}$. Surgery was performed with 5 patients under slight hypothermia and the other 5 under normothermia, with a similar intramucosal $\mathrm{pH}$ occurring at the end of extracorporeal circulation in all these patients $(7.25 \pm 0.07$ under hypothermia, and $7.27 \pm 0.09$ under normothermia).

The mean intramucosal $\mathrm{pH}$ values during the patients' evolution in the pediatric intensive care unit are shown in table III. As compared with the intramucosal $\mathrm{pH}$ on admission, the patients had a significant rise in intramucosal $\mathrm{pH}$

\begin{tabular}{|c|c|c|c|}
\hline \multicolumn{4}{|c|}{$\begin{array}{l}\text { Table II - pHi values and mean of } 10 \text { children in } 3 \text { three situations: } \\
\text { no dobutamine, } 5 \mathrm{mcg} / \mathrm{kg} / \mathrm{min} \text {, and } 10 \mathrm{mcg} / \mathrm{kg} / \mathrm{min} \text { dobutamine }\end{array}$} \\
\hline & Jo dobutamine & $5 \mathrm{mcg} / \mathrm{kg} / \mathrm{min}$ & $10 \mathrm{mcg} / \mathrm{kg} / \mathrm{min}$ \\
\hline pHi & 7.32 & 7.27 & 7.26 \\
\hline $\mathrm{pHi}$ & 7.09 & 7.01 & 7.52 \\
\hline $\mathrm{pHi}$ & 7.06 & 7.10 & 7.55 \\
\hline $\mathrm{pHi}$ & 7.09 & 7.05 & 7.17 \\
\hline $\mathrm{pHi}$ & 7.29 & 7.26 & 7.29 \\
\hline $\mathrm{pHi}$ & 7.18 & 7.14 & 7.30 \\
\hline $\mathrm{pHi}$ & 7.23 & 7.28 & 7.55 \\
\hline $\mathrm{pHi}$ & 7.20 & 7.08 & 7.37 \\
\hline $\mathrm{pHi}$ & 7.34 & 7.42 & 7.18 \\
\hline $\mathrm{pHi}$ & 7.18 & 7.04 & 7.08 \\
\hline$($ Mean \pm S.D. $)$ & $\begin{array}{c}7.17 \pm \\
0.11\end{array}$ & $\begin{array}{c}7.14 \pm \\
0.11\end{array}$ & $\begin{array}{cc}7.35 \pm & \chi_{\mathrm{r}}^{2}=4.55 \\
0.15 & \mathrm{p}=0.103\end{array}$ \\
\hline
\end{tabular}

\begin{tabular}{|c|c|c|c|c|c|}
\hline \multicolumn{6}{|c|}{ Table III - pHi values and mean of during the internation. } \\
\hline & n admission & After $4 \mathrm{hr}$ & After $8 \mathrm{hr}$ & After $12 \mathrm{hr}$ & After $24 \mathrm{hr}$ \\
\hline $\mathrm{pHi}$ & 7.21 & 7.55 & 7.30 & 7.21 & 7.44 \\
\hline $\mathrm{pHi}$ & 7.13 & 7.37 & 7.22 & 7.31 & 7.35 \\
\hline $\mathrm{pHi}$ & 7.09 & 7.10 & 7.26 & 7.29 & 7.54 \\
\hline $\mathrm{pHi}$ & 7.15 & 7.18 & 7.40 & 7.50 & 7.30 \\
\hline $\mathrm{pHi}$ & 7.45 & 7.57 & 7.36 & 7.53 & 7.43 \\
\hline $\mathrm{pHi}$ & 7.00 & 7.19 & 7.24 & 7.33 & 7.33 \\
\hline $\mathrm{pHi}$ & 7.37 & 7.29 & 7.19 & 7.36 & 7.23 \\
\hline $\mathrm{pHi}$ & 7.19 & 7.16 & 7.22 & 7.13 & 7.41 \\
\hline $\mathrm{pHi}$ & 7.27 & 7.14 & 7.16 & 7.25 & 7.38 \\
\hline $\mathrm{pHi}$ & 7.16 & 7.19 & 7.30 & 7.29 & 7.39 \\
\hline \multirow[t]{2}{*}{ (Mean \pm S.D. $)$} & $7.20 \pm$ & $7.27 \pm$ & $7.26 \pm$ & $7.32 \pm$ & $7.38 \pm$ \\
\hline & $0.13^{*}$ & 0.16 & 0.07 & $0.12 *$ & $0.08 *$ \\
\hline
\end{tabular}

after 12 hours, and this measurement remained stable after 24 hours ( $\mathrm{p}=0.0459$ ) (Fig. 2).

The patient's hemodynamic picture remained stable, with adequate hemoglobin saturation levels, and no metabolic or respiratory acidosis occurred, their mean hematocrit value being $33 \%$. Only 3 patients had transitory hypotension, which was accompanied in 2 patients by heart rhythm disorders (junctional rhythm or bradycardia) during the immediate postoperative period.

None of the patients had renal failure, developed a multiple organ or system dysfunction, or died. All patients were removed from mechanical pulmonary ventilation without any intercurrent anomalies and were released from the pediatric intensive care unit 6 to 8 hours after extubation. Hospitalization time in this unit was at least 1 day and at most 3 days.

\section{Discussion}

During states of shock, a loss of the splanchnic selfregulation mechanism occurs, and both the humoral and neural mediators produce a selective vasoconstriction, leading to splanchnic ischemia. Note that the gastrointestinal tractus has endocrine, metabolic, immunologic, and barrier functions, in addition to its role in food absorption, and can therefore no longer be viewed as a passive organ. Intestinal ischemia and reperfusion can bring about an increase in permeability, allowing bacterial or toxin translocation to oc-

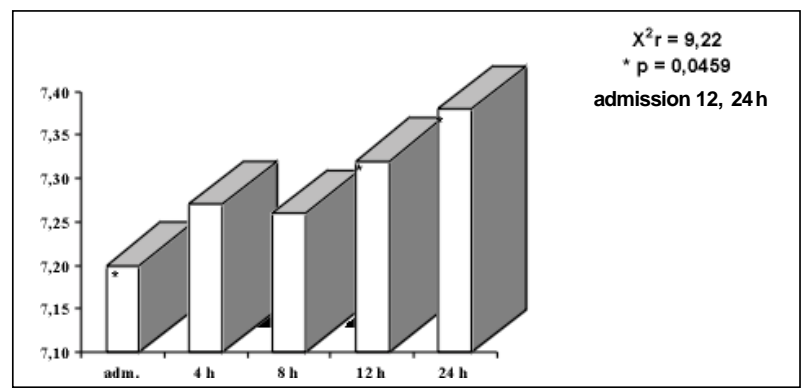

Fig. 2 - Graphical representation of elevation and normalization of pHi of the 10 patients during the first $24 \mathrm{hr}$ after admission to the pediatric intensive care unit. 
cur, invading the portal circulation. Inadequate hepatic perfusion leads to a decreased clearance of bacteria and their products. Intestinal ischemia can be an important cause of multiple organ failure and death in critically ill patients ${ }^{8}$.

The use of intramucosal $\mathrm{pH}$ measurements to predict complications after surgery was studied by Fiddian-Green and Baker ${ }^{9}$, who measured intramucosal $\mathrm{pH}$ in 85 patients in the postoperative period of elective cardiac surgery and compared it with other monitoring methods. The high sensitivity of this method led the authors to recommend the utilization of intramucosal $\mathrm{pH}$ to reduce the risks of complications, without increasing the risks for the patients. In studies carried out by Mythen and Webb ${ }^{10,11}$ on a total of 51 patients, an increase occurred in the number of complications in elective surgeries, with an increase in hospitalization costs in patients with a low gastric intramucosal $\mathrm{pH}$ during surgery; 14 patients developed complications ( 7 with multiple organ dysfunction) and 6 died.

During and after extracorporeal circulation, an increase in mediators causing vasoconstriction occurs, mainly in the levels of circulating angiotensin II, the hormone responsible for selective splanchnic vasoconstriction, being potentially able to alter the intramucosal $\mathrm{pH}$. Gaer et $\mathrm{al}^{12}$ compared the gastric tonometry alterations with the use of pulsatile and nonpulsatile flow and found a reduction in gastrointestinal perfusion, with gastric intramucosal acidosis and the development of postoperative complications. Landow et $\mathrm{al}^{13}$ observed a drop in intramucosal $\mathrm{pH}$ during extracorporeal circulation, which continued even after reheating.

The data reported in the literature concern adults; in our study, we selected children in the immediate postoperative period of corrective surgeries congenital cardiopathies with extracorporeal circulation, to observe and assess the applicability of this kind of monitoring and to characterize the evolution of this variable (intramucosal $\mathrm{pH}$ ) during the immediate postoperative period. The definition of a normal behavior curve is the first step toward the subsequent definition of its role and of the true benefit of using it in complicated cases.

Volemic replacement may be insufficient to maintain intestinal perfusion and improve the intramucosal $\mathrm{pH}$ during the immediate postoperative period of cardiac surgeries. It seems that adrenergic agents play an important role in the improvement of splanchnic circulation and in the reversal of intramucosal acidosis, and dobutamine seems to be an effective agent in the improvement in splanchnic blood flow ${ }^{14}$. Inotropic support is usually necessary after heart surgery, particularly when long lasting myocardial ischemia is present. In the pediatric intensive care unit, the great majority of children are placed on dobutamine during the immediate postoperative period and until they become hemodynamically stable, always after correction of volemia, of hemoglobin, and of metabolic acidosis, whenever necessary. In this study, we attempted to assess whether progressive increases in the drug would bring about a better splanchnic flow normalization response during the first hours after admission to the pediatric intensive care unit.

In addition to its use as a diagnostic method, some au- thors suggest monitoring intramucosal $\mathrm{pH}$ for therapeutic evaluation and triaging purposes. Comparing dobutamine infusion and infusion of packed red blood cells in 21 septic patients, Silverman and Tuma ${ }^{15}$ concluded that it was better to give dobutamine than packed red blood cells to reverse intramucosal acidosis. Dobutamine also seems to prevent the reduction of the intestinal blood flow during endotoxemia; consequently its prophylactic use can limit intestinal ischemia and prevent the development of multiple organ and system dysfunction ${ }^{16}$. Hernández et al ${ }^{17}$ obtained a greater improvement in intramucosal $\mathrm{pH}$ using dobutamine in patients with inflammatory systemic response syndrome and shock than with amrinone.

According to Parviainen et al ${ }^{18}$, the effects of dobutamine on intestinal perfusion during the cardiac postoperative period may not be uniform. In their article, they report that dobutamine increased cardiac output, splanchnic flow, and systemic and splanchnic oxygen transport $\left(\mathrm{TO}_{2}\right)$, but splanchnic $\mathrm{O}_{2}$ consumption was not altered (leading to a reduction in systemic and regional $\mathrm{O}_{2}$ extraction). Intramucosal $\mathrm{pH}$ was not different between the control and the normal cardiac output groups, but it was lower in the group with low cardiac output, suggesting an alteration in the flow distribution within the splanchnic territory.

In our cohort, several patients maintained a low intramucosal $\mathrm{pH}(\mathrm{pHi}<7.32)$, without major clinical alterations, even after the initial volemic replacement by plasma or albumin or even packed red blood cells. Patients had an increase in intramucosal $\mathrm{pH}$ as dobutamine was progressively increased, but the values were not statistically significant. With the $5 \mathrm{mcg} / \mathrm{kg} / \mathrm{min}$ dose, no increase occurred in the intramucosal $\mathrm{pH}$, but with $10 \mathrm{mcg} / \mathrm{kg} / \mathrm{min}$ dobutamine it reached a value considered normal (7.32), which might reflect a recovery in the intestinal blood flow, either by spontaneous recovery from extracorporeal circulation or by the use of the inotropic drug. Because we did not use subgroups with and without dobutamine, we cannot define whether an actual benefit was brought about by the use of the drug.

Not all authors agree that inotropic drugs have this improving effect on intramucosal $\mathrm{pH}$. A study by Uusaro et al ${ }^{19}$ suggests that patients with an uncomplicated postoperative period might tolerate a low intramucosal $\mathrm{pH}$ for a short time without ulterior complications, whereas in another study they conclude that dobutamine seems to improve splanchnic perfusion during the immediate postoperative period of cardiac surgery ${ }^{20}$.

Niinikoski and Kuttila ${ }^{21}$ reported an initial drop in the intramucosal $\mathrm{pH}$ after cardiac surgery with extracorporeal circulation. This drop reached its lowest values by the end of surgery and during the first 3 hours of hospitalization in the pediatric intensive care unit, and later on the patients a slow improvement in the intramucosal $\mathrm{pH}$, similar to our own experience. In some studies, even using inotropic and vasodilating substances, no postoperative normalization of the intramucosal $\mathrm{pH}$ was observed $24 \mathrm{hrs}$ after $\operatorname{admission}^{22,23}$.

Rey et al ${ }^{24}$ analyzed the postoperative intramucosal 
$\mathrm{pH}$ of children and found that its decrease preceded hemodynamic complications, whereas Casado-Flores et al ${ }^{25}$ found a higher mortality rate in patients with an intramucosal pH below 7.30 on admission.

In our work, intramucosal $\mathrm{pH}$ stabilized $12 \mathrm{hr}$ after patients entered the intensive care unit, where they all received dobutamine. Despite the low initial values of the intramucosal $\mathrm{pH}$, no patient experienced multiple organ dysfunction or died. So many questions still must be addressed, such as how long can the low intramucosal $\mathrm{pH}$ levels be maintained without further consequences.

In 19 trauma patients, Kirton et al $^{26}$, observed that survivors who were unable to normalize their intramucosal $\mathrm{pH}$ within the first $24 \mathrm{hr}$ had an increased global time of stay in the hospital and in the intensive care unit. The monitoring of the gastric intramucosal $\mathrm{pH}$ may therefore benefit patients at risk of developing low cardiac output or shock and also to those whose hemodynamic variables are impossible to monitor ${ }^{27}$.

This experience enabled us to conclude that tonometry is a safe technique, easy to perform, and uncomplicated, even in the pediatric population.

In summary, hemodynamic monitoring with gastric tonometry is, according to the literature, a valuable procedure during the immediate postoperative period of cardiac surgery in children. In our patients, intramucosal $\mathrm{pH}$ rose to normal values $12 \mathrm{hr}$ after cardiac surgery, showing the probable normalization of blood flow in the gastric region.

Invasive hemodynamic measurements provide us with more data and greater safety for the change of inotropic and vasoactive drug dosages, yet major difficulties exist for their regular use in pediatrics. Perhaps gastric tonometry can improve the titration of these drugs in pediatric patients with severe hemodynamic instability. As we had no cases of multiple organ dysfunction or low cardiac output in our cohort sample, we were unable to evaluate the intramucosal $\mathrm{pH}$ alterations in this kind of patient. Our results can, however, be used as a guide to outline the behavior of intramucosal $\mathrm{pH}$ during the immediate postoperative period of cardiac surgery in children who do well. Dobutamine may be partially responsible for the improvement in splanchnic circulation, thus reducing the risks of postoperative complications, but proper conclusions need targeted studies to define its role.

Controlled, randomized clinical studies, with protocols accompanied by intramucosal $\mathrm{pH}$ monitoring should be carried out before dobutamine is used routinely in pediatric patients after cardiac surgery.

\section{References}

1. Gutierrez G. Cellular energy metabolism during hypoxia. Crit Care Med 1991; 19: 619-26.

2. Grum CM. Tissue oxygenation in low flow states and during hypoxemia. Crit Care Med 1993; 21: S44-S9.

3. Astiz ME, Rackow EC. Assessing perfusion failure during circulatory shock. Crit Care Clin 1993; 9: 299-312.

4. Haglund U, Fiddian-Green RG. Assessment of adequate tissue oxygenation in shock and critical illness - oxygen transport in sepsis.Bermuda, April 1+2, 1989 (conference), Int Care Med 1989; 15: 475-7.

5. Silverman HJ. Gastric tonometry: an index of splanchnic tissue oxygenation? Crit Care Med 1991; 19: 1223-4.

6. Fiddian-Green RG. Gastric intramucosal pH, tissue oxygenation and acid-base balance. Br J Anaeth 1995; 74: 591-606.

7. Heard SO, Helsmoortel CM, Kent JC, Shahnarian A, Fink MP. Gastric tonometry in healthy volunteers: effect of ranitidine on calculated intramural $\mathrm{pH}$. Crit Care Med 1991; 19: 271-4.

8. Fiddian-Green RG. Splanchnic ischaemia and multiple organ failure in the critically ill. Ann R Coll Surg Engl 1988; 70: 128-34.

9. Fiddian-Green RG, Baker S. Predictive value of the stomach wall $\mathrm{pH}$ for complications after cardiac operations: comparison with other monitoring. Crit Care Med 1987; 15: 153-6.

10. Mythen MG, Webb AR. The role of gut mucosal hypoperfusion in the pathogenesis of post-operative organ dysfunction. Int Care Med 1994; 20: $203-9$.

11. Mythen MG, Webb AR. Intra-operative gut mucosal hypoperfusion is associated with increased post-operative complications and cost. Int Care Med 1994; 20: 99-104.

12. Gaer JAR, Shaw ADS, Wild R, et al. Effect of cardiopulmonary bypass on gastrointestinal perfusion and function. AnnThorac Surg 1994; 57: 371-5.

13. Landow L, Phillips DA, Heard SO, Prevost D, Vandersalm TJ, Fink MP. Gastric tonometry and venous oximetry in cardiac surgery patients. Crit Care Med 1991; 19: 1226-33.

14. Vincent J-L, Schmartz D, Backer D. Augmentation of blood flow. In: Pinsky MR, Dhanaut J-F, Artigas A. Update in Intensive Care and Emergency Medicine. Ed.. Belgium: Springer-Verlag, Brussels 1996; 23: 153-64.

15. Silverman HJ, Tuma P. Gastric tonometry in patients with sepsis: effects of dobutamine infusions and packed red blood cell transfusions. Chest 1992; 102: 184-8.
16. Schmidt H, Secchi A, Wellmann R, Böhrer H, Martin E. Effect of dobutamine on intestinal villus blood flow during normotensive endotoxemia in rats. In: 25th Educational and Scientific Symposium, New Orleans, 1996. Crit Care Med 1996; 24: A99.

17. Hernández G, Bugedo G, Castillo L, et al. Effect of amrinone and dobutamine on $\mathrm{pHi}$ and hemodynamics in septic patients. In: 24th Educational and Scientific Symposium, San Francisco, 1995. Crit Care Med 1995; 23: A163.

18. Parviainen I, Ruokonen E, Takala J. Dobutamine-induced dissociation between changes in splanchnic blood flow and gastric intramucosal $\mathrm{pH}$ after cardiac surgery. Br J Anaesth 1995; 74: 277-82.

19. Uusaro A, Ruokonen E, Takala J. Gastric mucosal $\mathrm{pH}$ does not reflect changes in splanchnic blood flow after cardiac surgery. Br J Anaesth 1995; 74: 149-54.

20. Uusaro A, Ruokonen E, Takala J. Splanchnic oxygen transport after cardiac surgery: evidence for inadequate tissue perfusion after stabilization of hemodynamics. Int Care Med 1996; 22: 26-33.

21. Niinikoski J, Kuttila K. Adequacy of tissue oxygenation in cardiac surgery: regional measurements. Crit Care Med 1993; 21: S77-S83.

22. Loick HM, Möllhoff T, Berendes E, HammelD, Prien TH. Effect of enoximone on gut oxygenation and endotoxin release following cardiopulmonary bypass. In: 25th Educational and Scientific Symposium, New Orleans, 1996. Crit Care Med 1996; 24: A30.

23. Berendes E, Möllhoff T, Deng M, Loick HM. Low-dose-dopexamine: effect on splanchnic oxygenation and endotoxin release after cardiopulmonary bypass. In: 25th Educational and Scientific Symposium, New Orleans, 1996. Crit Care Med 1996; 24: A31.

24. Rey CC, Tarrío FR, Campaña MB, Cid JL-H, Muñoz J, Martínez-Romillo PD Tonometría gástrica en niños críticamente enfermos: estudio preliminar. An Esp Pediatr 1995; 42: 424-8.

25. Casado-Flores J, Mora E, Perez-Corral F, Martínez-Azagra A, García-Teresa A, Ruiz-Lópes MJ. Prognostic value of gastric intramucosal $\mathrm{pH}$ in critically ill children. Crit Care Med 1998; 26: 1123-7.

26. Kirton OC, Windsor J, Wedderburn R, et al. Failure of splanchnic resuscitation in the acutely injured trauma patient correlates with multiple organ system failure and length of stay in the ICU. Chest 1998; 113: 1064-9.

27. Arnold J, Hendriks J, Ince $\mathrm{C}$, Bruining $\mathrm{H}$. Tonometry to assess the adequacy of splanchnic oxygenation in critically ill patient. Int Care Med 1994; 20: 452-6. 